Original Research Paper

\title{
Local Binary Pattern for the Evaluation of Surface Quality of Dissimilar Friction Stir Welded Ultrafine Grained 1050 and 6061-T6 Aluminium Alloys
}

\author{
${ }^{1}$ Akshansh Mishra and ${ }^{2}$ Rajat Sarawagi \\ ${ }^{I}$ Department of Mechanical Engineering, Politecnico Di Milano, Italy \\ ${ }^{2}$ Samsung Research Institute, Noida, Uttar Pradesh, India
}

\author{
Article history \\ Received: 08-07-2020 \\ Revised: 24-07-2020 \\ Accepted: 27-07-2020 \\ Corresponding Author: \\ Akshansh Mishra \\ Department of Mechanical \\ Engineering, Politecnico Di \\ Milano, Italy \\ Email: \\ akshansh.frictionwelding@gmail.com
}

\begin{abstract}
Friction Stir Welding process is an advanced solid-state joining process which finds application in various industries like automobiles, manufacturing, aerospace and railway firms. Input parameters like tool rotational speed, welding speed, axial force and tilt angle govern the quality of Friction Stir Welded joint. Improper selection of these parameters further leads to fabrication of the joint of bad quality resulting groove edges, flash formation and various other surface defects. In the present work, a texture based analytic machine learning algorithm known as Local Binary Pattern (LBP) is used for the extraction of texture features of the Friction Stir Welded joints which are welded at a different rotational speed. It was observed that LBP algorithm can accurately detect any irregularities present on the surface of Friction Stir Welded joint.
\end{abstract}

Keywords: Machine Learning, Friction Stir Welding, Local Binary Pattern, Machine Vision

\section{Introduction}

Friction Stir Welding is a solid state joining process which was developed by The Welding Institute (TWI) mainly for joining the light-weight materials like aluminium and magnesium alloys (Mishra and Ma, 2005; Pratik and Vishvesh, 2019; Ramona and Santos Jorge, 2013). The Friction Stir weldability of aluminium alloys is compared to other conventional fusion welding process shown in Fig. 1. Friction Stir Welding process results high quality welds but the welding performance mainly depends on the proper selection of various input parameters like pin temperature, tool rotational speed, feed rate, welding speed, temperature distribution, rotating tool torque, applied downward forging force on tool shoulder etc.

The working mechanism of the Friction Stir Welding process is shown in the Fig. 2.

The main beauty of the Friction Stir Welding process is that it uses non-consumable metallic tool which is harder than the base material to be joined (Rai et al., 2011). The tool consists of a shoulder and pin as shown in the Fig. 3b). The tool is plunged inside the base material by applying a downward force. The Friction Stir
Welding tool possesses two types of speed i.e., Rotational speed and Traverse speed in the welding direction. Due to the rotation of the rotating tool there is a generation of friction between the work piece and the rotating tool which results in plastic deformation the work piece as shown in the Fig. 3c).

Due to the generated localized heat, the work piece get soften around the probe or pin region which results in the movement of soften or plasticized material from the front part of the probe to the back part of the probe. The welded joint is formed by deforming the material at temperatures below the melting point of parent material (Mijajlović and Milčić, 2012). At a very cold welding conditions defects such as void formation and non-bonding can occur while at very hot welding condition issues such as degradation of the strength of the joint can occur as well as there is a formation of collapsible nugget within the stir zone occurs (Rudrapati, 2019).

In the present work, a machine learning algorithm called Local Binary Pattern (LBP) has been developed for evaluating the surface defects like lack of penetration and flash formation of dissimilar Friction Stir Welded Ultrafine Grained 1050 and 6061-T6 Aluminum Alloys. 


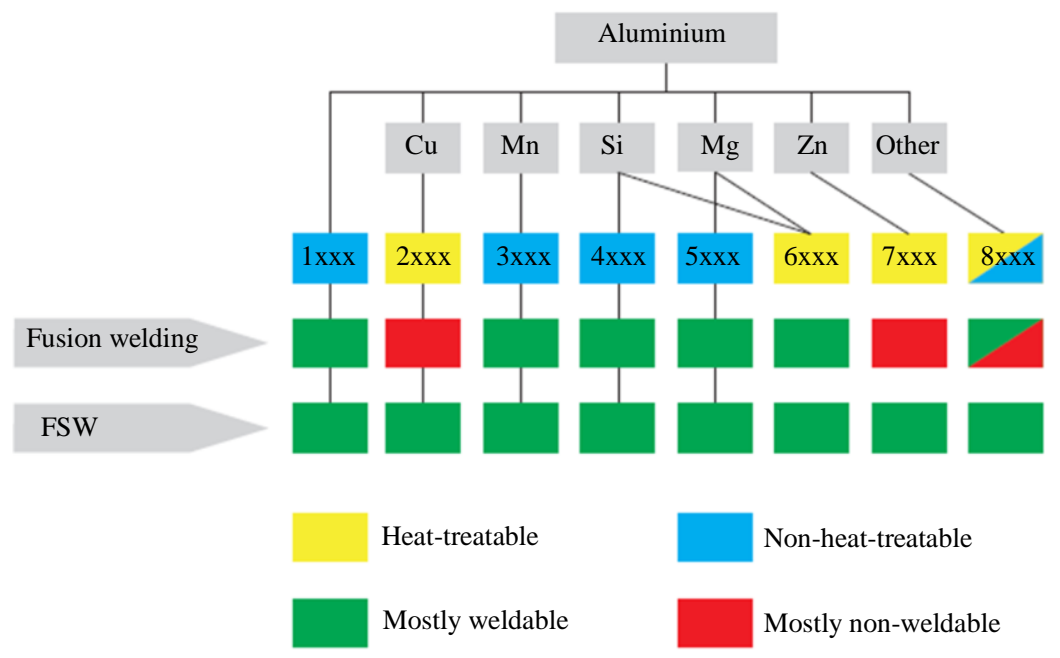

Fig. 1: Comparison of the weldability of different aluminium alloys by conventional and Friction Stir Welding process (Pratik and Vishvesh, 2019)

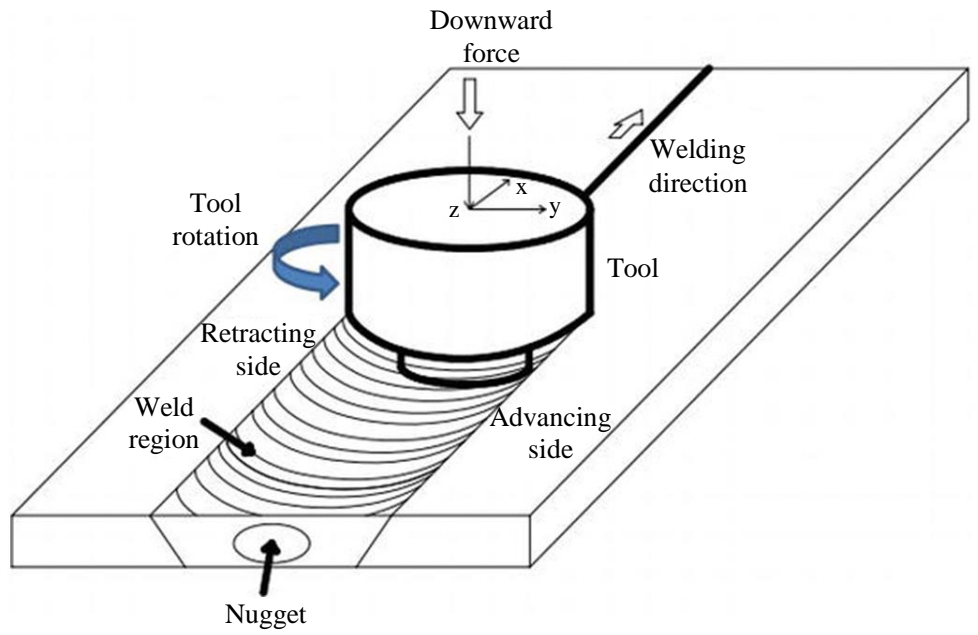

Fig. 2: Mechanism of Friction Stir Welding process (Ramona and Santos Jorge, 2013)

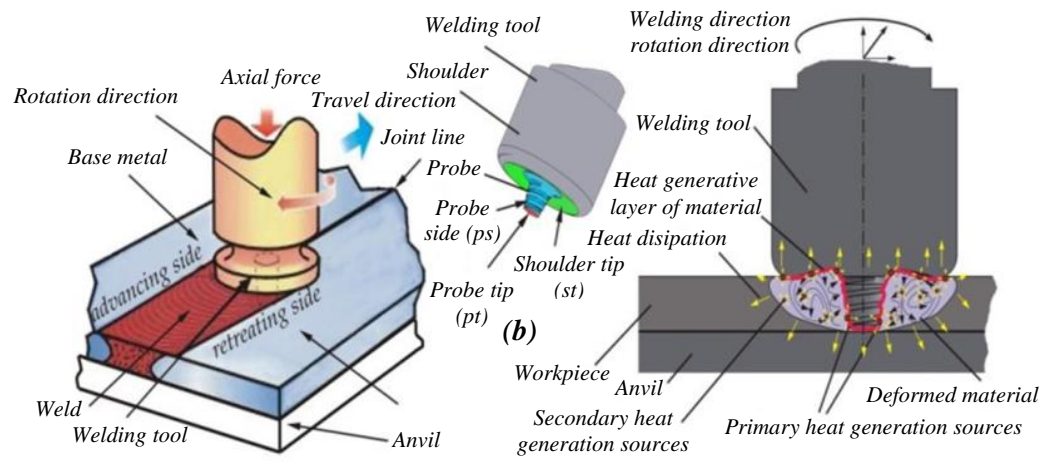

(a)

(c)

Fig. 3: (a) Friction Stir Welding Setup, (b) Tool Nomenclature, (c) Heat generation and plastic deformation in FSW process (Mijajlović, 2012) 


\section{Working of Local Binary Pattern (LBP)}

Local Binary Pattern is an important image texture analysis machine vision algorithm which is tolerant against any type of illumination changes in a real time application (Cai et al., 2020). Local Binary Pattern creates a grey value difference between the neighbourhood pixels and the centre pixel in the sampling area. In a rectangular neighbourhood with size of $3 \times 3$, Local Binary Pattern is defined. Firstly, conversion of the colour image into grey scale image is done with grey scale value of $0 \sim 255$. As a sampling point, pixels of the rectangular area are used. $f_{0}$ is the grey value of the centre pixel and $f_{1}, f_{2}, f_{3} \ldots, f_{8}$ are the grey scale values of the 8 pixels around it. The corresponding position is encoded as 1 when $f_{i} \geq f_{0}$. The corresponding position is encoded as 0 when $f_{i}<f_{0}$ as shown in the Fig. 4.

Equation 1 describes the coding formula for Local Binary Pattern algorithm:

$$
\begin{aligned}
& \operatorname{LBP}(C)=\sum_{i=1}^{8} S\left(f_{i}, f_{0}\right) \cdot 2^{i-1} \\
& S\left(f_{i}, f_{0}\right)=\left\{\begin{array}{l}
\left\{1, f_{i}-f_{0} \geq 0\right. \\
\left\{0, f_{i}-f_{0}<0\right.
\end{array}\right.
\end{aligned}
$$

Kamani et al. (2011) used Local Binary Pattern for classification of car body and automatic paint defect detection. It was observed that the identification and classification of defects can be done with high accuracy. Mahram et al. (2012) detected cracks and wood knots in order to classify stable and strong woods by using Local Binary Pattern algorithm. Aghdam et al. (2012) worked on the defect detection using decision trees applied to
LBP based features. The results showed that in comparison to other traditional schemes, the proposed classification system is faster. Luo et al. (2018) for timeefficient steel surface defect classification used generalized completed Local Binary Pattern. The results showed that the method can be implemented in online monitoring system for hot-rolled steel strip.

\section{Experimental Procedure}

Friction Stir Welding was carried out on $2 \mathrm{~mm}$ thick plate of commercial AA 6061-T6 and Ultrafine grained 1050 aluminium alloy plates (Sun et al., 2016). The material used for Friction Stir Welding tool was tool steel whose shoulder geometry was concave shaped. During welding operation, constant load of $8000 \mathrm{KN}$ was applied at a constant rotational speed of $800 \mathrm{rpm}$ and varying traverse speed of 400, 600, 800, 1000 $\mathrm{mm} / \mathrm{min}$. Figure $5 \mathrm{a}$ shows the dissimilar Friction Stir Welded joint obtained at tool rotational speed of 800 $\mathrm{rpm}$ and $600 \mathrm{~mm} / \mathrm{min}$ while Fig. 5b shows the dissimilar Friction Stir Welded joint obtained at tool rotational speed of $800 \mathrm{rpm}$ and tool traverse speed of $800 \mathrm{~mm} / \mathrm{min}$. Similarly, Fig. 6a shows the dissimilar Friction Stir Welded joint obtained at the tool rotational speed of $800 \mathrm{rpm}$ and tool traverse speed of 400 $\mathrm{mm} / \mathrm{min}$, Fig. $6 \mathrm{~b}$ shows the joint obtained at the tool rotational speed of $800 \mathrm{rpm}$ and tool traverse speed of $600 \mathrm{~mm} / \mathrm{min}$, Fig. 6c shows the joint obtained at the tool rotational speed of $800 \mathrm{rpm}$ and tool traverse speed of $800 \mathrm{~mm} / \mathrm{min}$, Fig. $6 \mathrm{~d}$ shows the joint obtained at the tool rotational speed of $800 \mathrm{rpm}$ and tool traverse speed of $1000 \mathrm{~mm} / \mathrm{min}$.

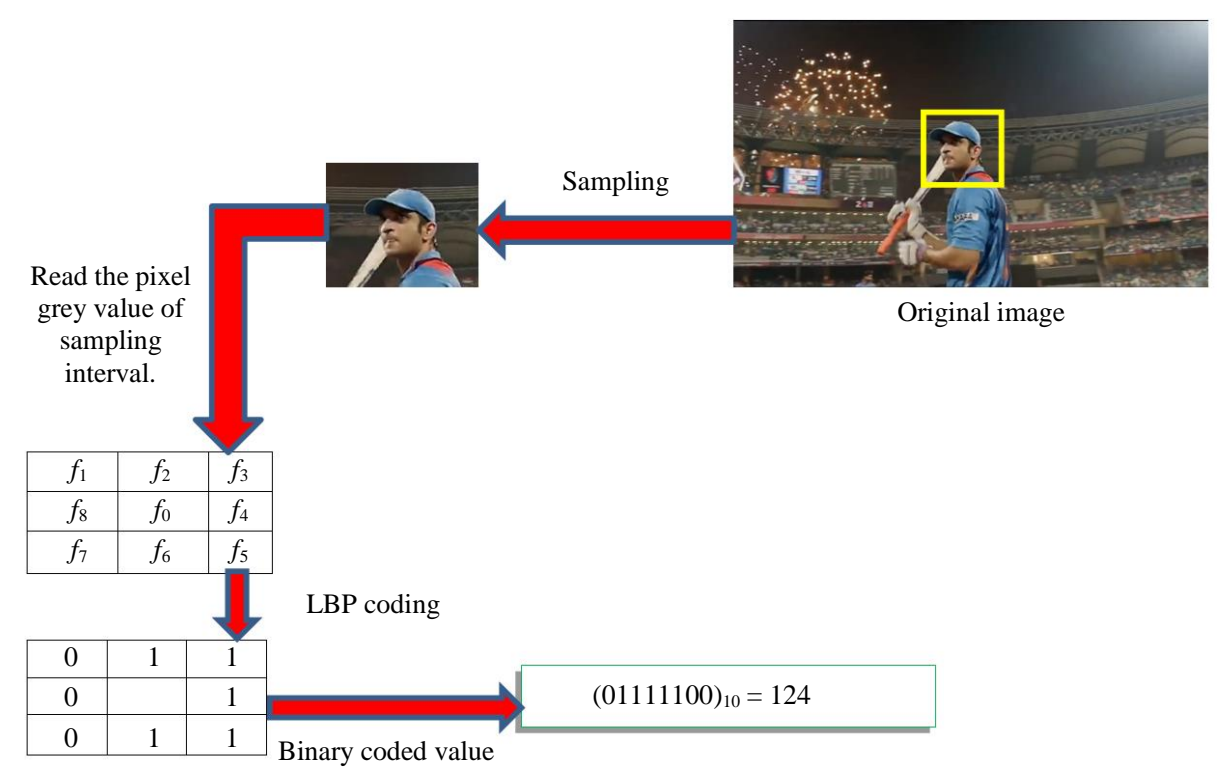

Fig. 4: Schematic diagram representing the working of Local Binary Operator 

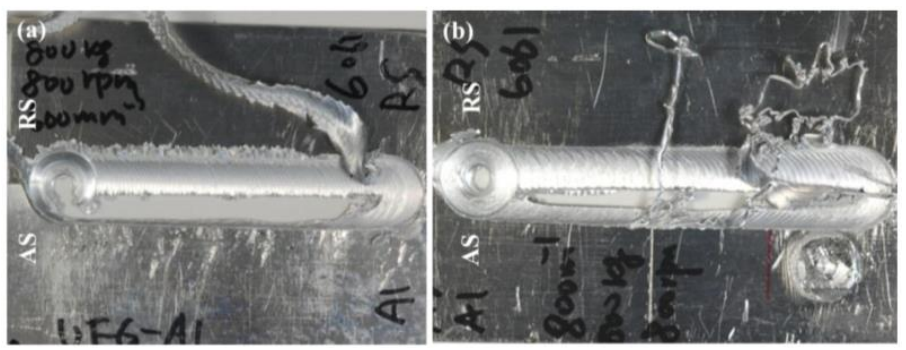

Fig. 5: Friction Stir Welded joints obtained at a constant tool rotational speed of $800 \mathrm{rpm}$ and tool traverse speeds of $600 \mathrm{~mm} / \mathrm{min}$ and $800 \mathrm{~mm} / \mathrm{min}$ (Sun et al., 2016)
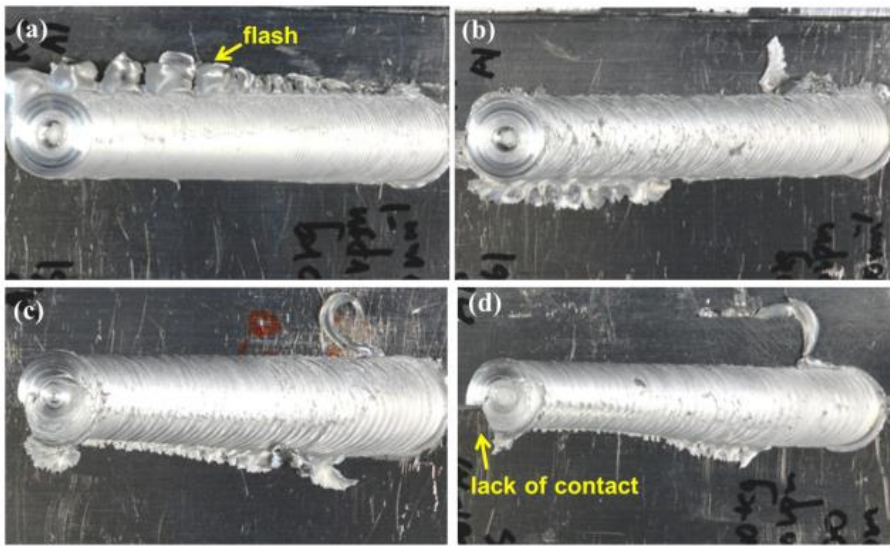

Fig. 6: Friction Stir Welded joints obtained at a constant rotational speed of $800 \mathrm{rpm}$ and varying traverse speeds of 400, 600, 800 , $1000 \mathrm{~mm} / \mathrm{min}$ (Sun et al., 2016)



Fig. 7: Steps taken for obtaining the grey image, LBP and histogram of the Friction Stir Welded joint 
The obtained images were cropped and were subjected to various operations as shown in the Fig.7.

The Python programming was used for coding the algorithm and to carry out the modelling.

\section{Results and Discussion}

The grey images, Local Binary Patterns and histograms of the Friction Stir Welded were obtained as shown in the Fig. 8-11. Local Binary Pattern can easily display the nonhomogeneous nature of the image. So, various surface defects like flash formation, groovy edges and lack of contact present in Friction Stir Welded joints can be easily detected by implementing Local Binary Patterns.
From Fig. 8 and 9 it is observed that when the 6061-T6 plate is on retreating side while ultrafine grained 1050 aluminium plate is on advancing side there is a lot of non-homogenity in the LBP converted image with few peak points in histogram. This nonhomogenous nature represents improper mixing of both alloy materials.

From Fig. 10 and 11 it is observed that when the ultrafine grained 1050 aluminium plate is on retreating side and 6061-T6 plate is on advancing side the LBP converted images show more homogenous nature than Fig. 8 and 9 and also more peak values are observed in histograms comparison to the histograms of Fig. 8 and 9.
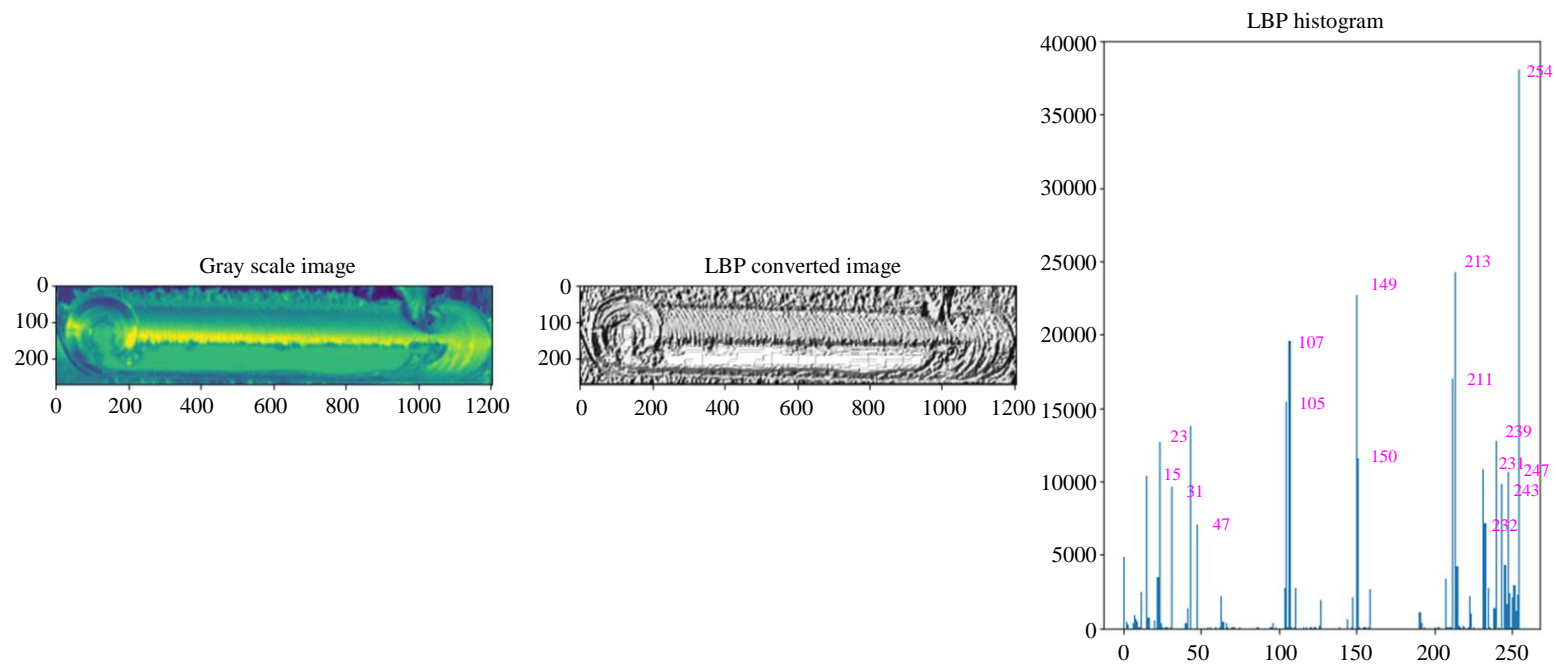

Fig. 8: Grey scale image, LBP Converted image and Histogram of Friction Stir Welded joint (6061-T6 on retreating side) obtained at the tool rotational speed of $800 \mathrm{rpm}$ and tool traverse speed of $600 \mathrm{~mm} / \mathrm{min}$

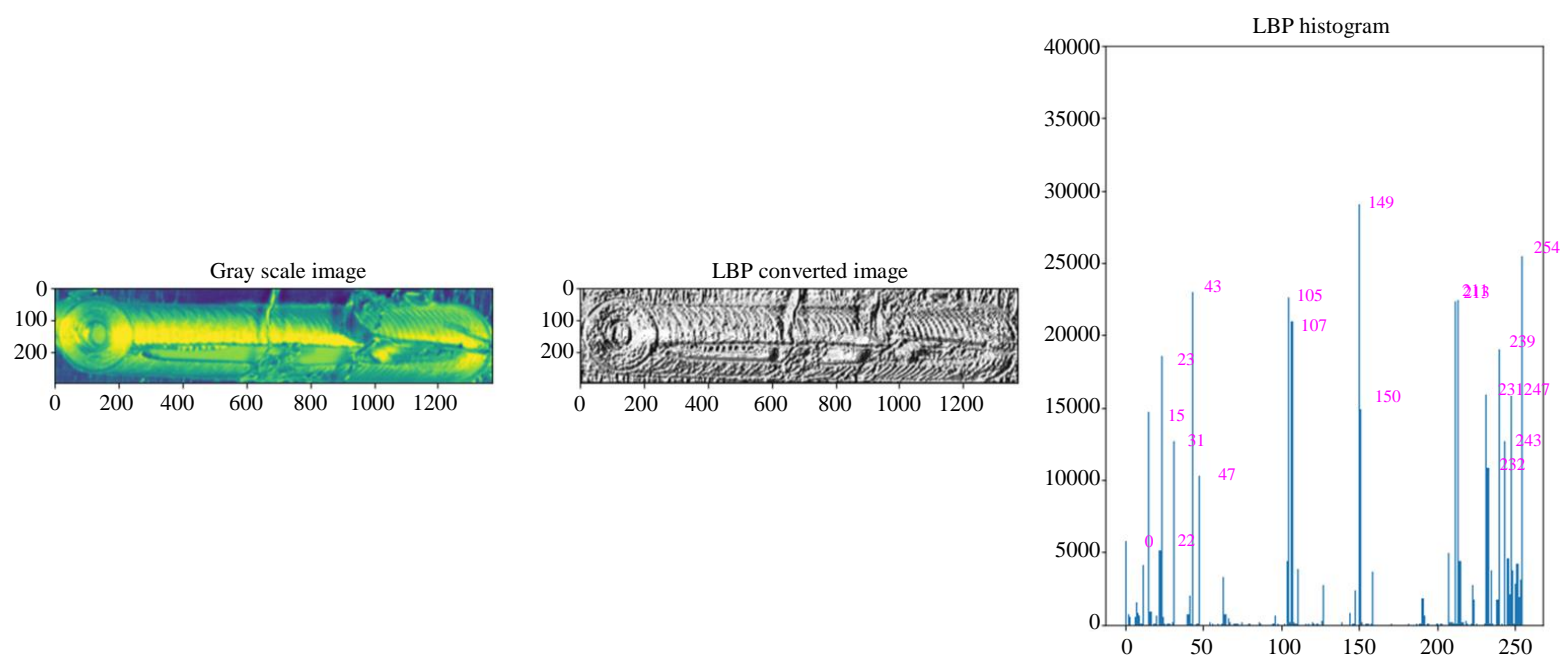

Fig. 9: Grey scale image, LBP Converted image and Histogram of Friction Stir Welded joint (6061-T6 on retreating side) obtained at the tool rotational speed of $800 \mathrm{rpm}$ and tool traverse speed of $800 \mathrm{~mm} / \mathrm{min}$ 

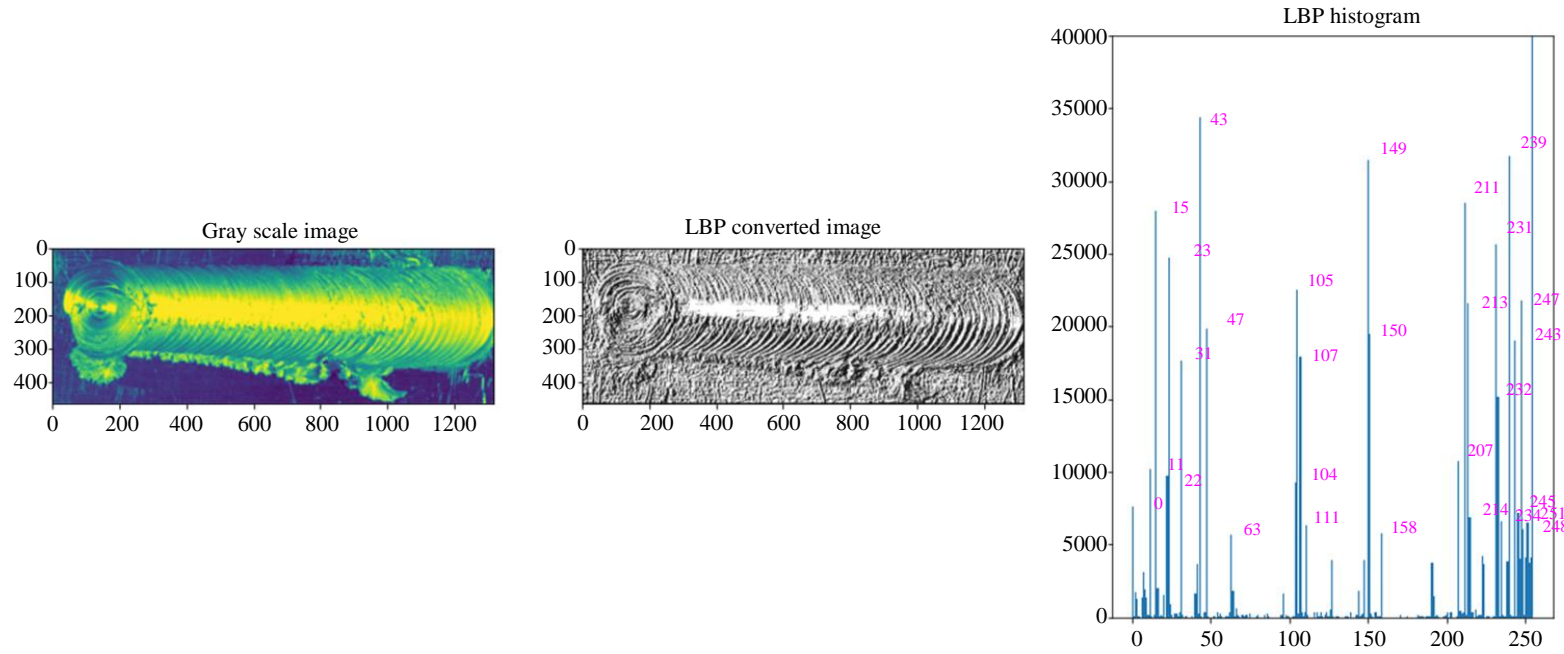

Fig. 10: Grey scale image, LBP Converted image and Histogram of Friction Stir Welded joint (6061-T6 on advancing side) obtained at the tool rotational speed of $800 \mathrm{rpm}$ and tool traverse speed of $800 \mathrm{~mm} / \mathrm{min}$
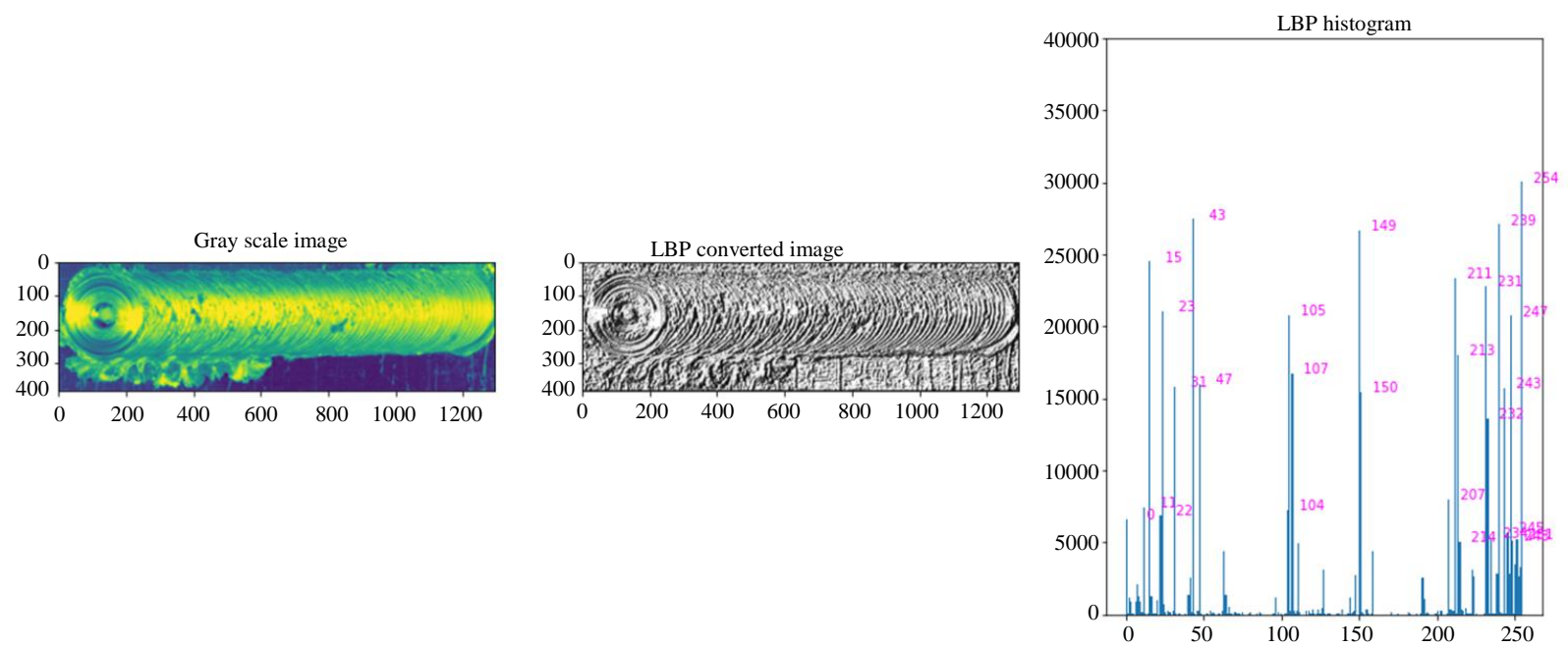

Fig. 11: Grey scale image, LBP Converted image and Histogram of Friction Stir Welded joint (6061-T6 on advancing side) obtained at the tool rotational speed of $800 \mathrm{rpm}$ and tool traverse speed of $600 \mathrm{~mm} / \mathrm{min}$

\section{Conclusion}

In this study, Local Binary Pattern algorithm is proposed for evaluating the surface quality of Friction Stir Welded joints. Local Binary Pattern algorithm easily validated the detection of surface defects like lack of contact and flash formation in Friction Stir Welded joints. It is observed that when 6061-T6 is on retreating side then the LBP converted image shows more non-homogenous nature in comparison to arrangement when 6061-T6 is on advancing side also the former arrangement shows less peak values in histograms. So, it can be concluded that Local Binary Pattern (LBP) algorithm can be successfully implemented in visual inspection and in real-time monitoring.

\section{Acknowledgment}

Authors would like to thanks to their parents for always being a motivation for the successful research projects. 


\section{Author's Contributions}

Akshansh Mishra: Designed the algorithms by using python programming.

Rajat Sarawagi: Done literature survey

\section{Ethics}

This article is original and contains unpublished material. The corresponding author confirms that all of the other authors have read and approved the manuscript and no ethical issues involved.

\section{References}

Aghdam, S. R., Amid, E., \& Imani, M. F. (2012, July). A fast method of steel surface defect detection using decision trees applied to LBP based features. In 2012 7th IEEE Conference on Industrial Electronics and Applications (ICIEA) (pp. 1447-1452). IEEE.

Cai, Y., Xu, G., Li, A., \& Wang, X. (2020). A Novel Improved Local Binary Pattern and Its Application to the Fault Diagnosis of Diesel Engine. Shock and Vibration, 2020.

Kamani, P., Noursadeghi, E., Afshar, A., \& Towhidkhah, F. (2011, November). Automatic paint defect detection and classification of car body. In 2011 7th Iranian Conference on Machine Vision and Image Processing (pp. 1-6). IEEE.

Luo, Q., Sun, Y., Li, P., Simpson, O., Tian, L., \& He, Y. (2018). Generalized completed local binary patterns for time-efficient steel surface defect classification. IEEE Transactions on Instrumentation and Measurement, 68(3), 667-679.

Mahram, A., Shayesteh, M. G., \& Jafarpour, S. (2012, July). Classification of wood surface defects with hybrid usage of statistical and textural features. In 2012 35th International Conference on Telecommunications and Signal Processing (TSP) (pp. 749-752). IEEE.
Mijajlović, M. (2012). Investigation and development of analytical model for estimation of amount of heat generated during FSW (Doctoral dissertation, $\mathrm{Ph}$. D. thesis, Faculty of Mechanical Engineering Nis, University of Nis, Nis, Serbia).

Mijajlović, M., \& Milčić, D. (2012). Analytical model for estimating the amount of heat generated during friction stir welding: application on plates made of aluminium alloy 2024 T351. Welding processes, 247-274.

Mishra, R. S., \& Ma, Z. Y. (2005). Friction stir welding and processing. Materials science and engineering: R: reports, 50(1-2), 1-78.

Pratik, H.S., \& Vishvesh, J. B. (2019). Friction stir welding of aluminium alloys: An overview of experimental findings-Process, variables, development and applications. Proceedings of the Institution of Mechanical Engineers, Part L: Journal of Materials: Design and Applications, 233(6), 1191-1226.

Rai, R., De, A., Bhadeshia, H. K. D. H., \& DebRoy, T. (2011). friction stir welding tools. Science and Technology of welding and Joining, 16(4), 325-342.

Ramona, G., \& Santos Jorge, F. D. (2013). Friction stir welding development of aluminium alloys for structural connections. Proceedings of the romanian academy, Series A, 14(1), 64-71.

Rudrapati, R. (2019). Recent Advances in Joining of Aluminum Alloys by Using Friction Stir Welding. In Mass Production Processes. IntechOpen.

Sun, Y., Tsuji, N., \& Fujii, H. (2016). Microstructure and mechanical properties of dissimilar friction stir welding between ultrafine grained 1050 and 6061-t6 aluminum alloys. Metals, 6(10), 249. 